\title{
Climate modulation of the Tibetan Plateau on haze in China
}

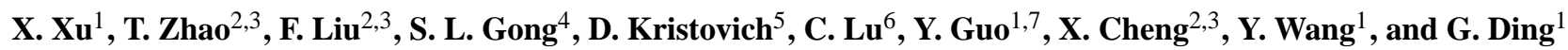 \\ ${ }^{1}$ State Key Laboratory of Severe Weather, Chinese Academy of Meteorological Sciences, Beijing 100081, China \\ ${ }^{2}$ Collaborative Innovation Center on Forecast and Evaluation of Meteorological Disasters, Nanjing University of Information \\ Science and Technology, Nanjing 210044, China \\ ${ }^{3}$ Key Laboratory for Aerosol-Cloud-Precipitation of China Meteorological Administration, Nanjing University of Information \\ Science \& Technology, Jiangsu 210044, China \\ ${ }^{4}$ Institute of Atmospheric Composition/Key Laboratory of Atmospheric Chemistry of China Meteorological Administration, \\ Chinese Academy of Meteorological Sciences, Beijing 100081, China \\ ${ }^{5}$ Climate and Atmospheric Science Section, Division of Illinois State Water Survey, Prairie Research Institute, University of \\ Illinois at Urban-Champaign, Champaign, IL 61820, USA \\ ${ }^{6}$ National Science Foundation, VA 22230, Arlington, Virginia, USA \\ ${ }^{7}$ Tiannan Observatory, Tianjin Meteorological Bureau, Tianjin 200350, China \\ Correspondence to: T. Zhao (tlzhao@nuist.edu.cn)
}

Received: 2 October 2015 - Published in Atmos. Chem. Phys. Discuss.: 26 October 2015

Revised: 21 January 2016 - Accepted: 22 January 2016 - Published: 8 February 2016

\begin{abstract}
Rapid increases in pollutant emissions in conjunction with stagnant meteorological conditions result in haze pollution in China. Recent frequent haze in China has attracted worldwide attention. Here we show a relationship between the haze events and Tibetan Plateau (TP)'s environment and climate changes. Based on observational data taken over recent decades, we identify central-eastern China (CEC) as a climatological large-scale "susceptible region" of frequent haze, which is harbored by the TP with its impact on midlatitude westerly winds. The observational and modeling studies demonstrate that the interannual variations in the thermal forcing of TP are positively correlated with the incidences of wintertime haze over CEC. Further analysis indicates that the climate warming of the TP induced changes in atmospheric circulation, driving frequent haze events in CEC. The frequent haze occurrences in CEC are consistent with decreasing winter monsoon winds, intensifying downward air flows and increasing atmospheric stability in the lower troposphere over the CEC in association with upstream plateau's thermal anomalies. Therefore, variations of haze in China are related to mechanical and thermal forcing by the TP. Our results also suggest that implications of the large TP topography for environment and climate changes should be taken into account for air pollution mitigation policies in China.
\end{abstract}

\section{Introduction}

Haze in poor visibility with high particulate matter (PM) or aerosol levels is a pervasive air quality problem facing China, posing a major challenge for public health (Huang et al., 2014; Zhang et al., 2015). The frequent haze pollution has been notable for hitting record high levels of PM pollution over central-eastern China (CEC) since 1961 (Ding and Liu, 2014). In January 2013, extremely severe and persistent haze events swept over much of CEC region. A large area of CEC from the North China Plain, including Beijing, across the Lower Yangtze Valley Plain to the Sichuan Basin, was blanketed in thick haze and smog for almost 1 month. It is estimated by the Chinese government that this wintertime haze covered a quarter of the total land area in China with 600 million people, half of the Chinese population, who were exposed to the haze air pollution (NDRC, 2013; Gu, 2013). China's National Meteorological Center released its first ever haze orange alert (CMA, 2010) in response to the air quality index frequently reaching hazardous levels for this regional haze event. The $\mathrm{PM}_{2.5}$ (PM with an aerodynamic diameter less than $2.5 \mu \mathrm{m}$ ) concentrations at 33 cities in the CEC region were more than $300 \mu \mathrm{g} \mathrm{m}^{-3}$ for longer than half a month, and some monitors reported hourly peak $\mathrm{PM}_{2.5}$ levels of $900 \mu \mathrm{g} \mathrm{m}^{-3}$, which is classified as "beyond 
index" (NDRC, 2013; Gu, 2013). The suffering of those in China from haze and poor air quality has attracted worldwide attention (Wang et al., 2014; Kan et al., 2012; Park et al., 2013; Zhao et al., 2013; Pope and Dockery, 2013; Chen et al., 2013b).

China has been experiencing increased air pollution, commonly attributed to the large increases in pollutant emissions associated with the rapid economic development. However, air quality is modulated by changes in meteorology and climate (Tagaris et al., 2009; Zhang et al., 2014; Wang et al., 2015). Accompanied by an unceasing increase in the Chinese pollutant emissions in recent decades, the CEC region has observed significant interannual variations of haze occurrences (Ding and Liu, 2014). The changing east Asian monsoon climate could also play an important role in the variations of haze events in CEC apart from the anthropogenic dimension of pollutant emission sources related to the rapid industrialization of China. The surface wind speed associated with east Asian monsoons has significantly weakened in both winter and summer in the last 3 decades (Xu et al., 2006; Oey et al., 2013). The weakening of the east Asian monsoons could increase air pollutants mainly by the changes in atmospheric circulation and weather conditions (Zhu et al., 2012; Niu et al., 2010). Weak advection of cold air, in conjunction with strong subsidence and stable atmospheric stratification, can easily produce a stagnation area in the lower troposphere, resulting in regional pollutant accumulations, which are favorable for the development of CEC haze events (Zhao et al., 2013). In addition, in the presence of high soil moisture, strong surface evaporation results in increases in the nearsurface relative humidity, which are also conducive to haze formation (Xiao et al., 2011). The contribution of the meteorological factors to the variance of the daily haze evolution was estimated to reach 0.68 , which could explain more than $2 / 3$ of the variance for the persistent severe haze events over CEC in January 2013 (Zhang et al., 2014). As a result of the changes in the east Asian winter monsoon climate, the Arctic sea ice decline could intensify haze pollution in CEC (Wang et al., 2015).

It is generally accepted that meteorological conditions in China are closely connected to the large topography of the Tibetan Plateau (TP) (Yanai et al., 1992; Xu et al., 2010; Wu et al., 2012; Ye and Wu, 1998). Precipitation, land surface temperature and surface air temperature have increased on the TP over the past decades (Zhong et al., 2011). The TP has exhibited the largest surface radiative flux changes induced by aerosols (e.g., black carbon and dust) contaminating snow and ice compared to any other snow- and ice-covered regions in the world (Qian et al., 2011). Aerosol transport and deposition have been increasingly polluting and even melting the snow- and ice-dominated wintertime TP (Ramanathan and Carmichael, 2008; Xu et al., 2009). This process leads to decreases in the snow and ice albedos, which could be largely responsible for climate change in the TP region (Hansen and Nazarenko, 2004). As one of the absorbing aerosols in the atmosphere, dust can influence the climate directly by modulating the radiation budget, affect the microphysical properties of clouds and alter the surface albedo of the ground covered by snow or glacier on the TP. Dust transport and depositions could have an impact on regional climate and environment over the TP (Lau et al., 2006, 2010; Huang et al., 2008; Liu et al., 2008; Chen et al., 2013a). The question remains whether the rapid changes in climate experienced by the TP could exert an influence on the haze variations in the downstream CEC region, the lower flatlands harbored by the large TP topography. The consequent processes linking the TP climate change with the CEC haze pollution should be highly possible and worth investigating, even though it is obvious that increasing anthropogenic pollutant emissions contribute to high haze frequency (Zhang et al., 2013). In this study, we attempt to determine the physical connection between climate change in the TP and haze occurrences in the CEC region to more comprehensively understand the large-area haze formation in China, especially with the background of global warming affecting the TP's environment and changes in its climate.

\section{Data and methods}

In this study, we used the observational records of visibility, weather phenomenon, relative humidity and $10 \mathrm{~m}$ wind from 1961 to 2012 archived at the China Meteorological Administration (CMA), and the meteorological variables of air temperature, winds and relative humidity from the reanalysis data generated by the US National Center for Environmental Prediction-National Center for Atmospheric Research (NCEP/NCAR). This study adopts a widely used comprehensive haze definition using surface in situ observations of visibility, relative humidity and weather phenomenon. The observed relative humidity of less than $90 \%$ is used to distinguish haze from fog under the visibility $<10 \mathrm{~km}$, (Schichtel et al., 2001; Doyle and Dorling, 2002; Ding and Liu, 2014). The Chinese $\mathrm{CO}_{2}$ emission data during 1961-2012 can be downloaded online from the website (http://cdiac.ornl.gov/ CO2_Emission/timeseries/national).

Following the studies of Yanai (1961); Yanai and Johnson (1993) and Yanai and Tomita (1998), the apparent heat source $\left(Q_{1}\right)$ and apparent moisture sink $\left(Q_{2}\right)$ are calculated. Atmospheric heat sources and moisture sinks are respectively gauged with the $Q_{1}$ and $Q_{2}$. As $Q_{1}$ includes $Q_{2}$ and radiative heating, here we only concentrate on the collective effect of apparent heating $\left(Q_{1}\right)$ over the TP. The heat source column (in units of $\mathrm{w} \mathrm{m}^{-2}$ ) over the TP is obtained with both horizontal and vertical integration of $Q_{1}$ over the TP area of $78-103^{\circ} \mathrm{E}$ and $28-38^{\circ} \mathrm{N}$, covering most of the region with an altitude higher than $3000 \mathrm{~m}$ (see the large TP rectangle in upper panel of Fig. 1) to form a one-dimensional variable representing the TP thermal forcing. The correlation coefficients between the TP heat source column and the meteoro- 

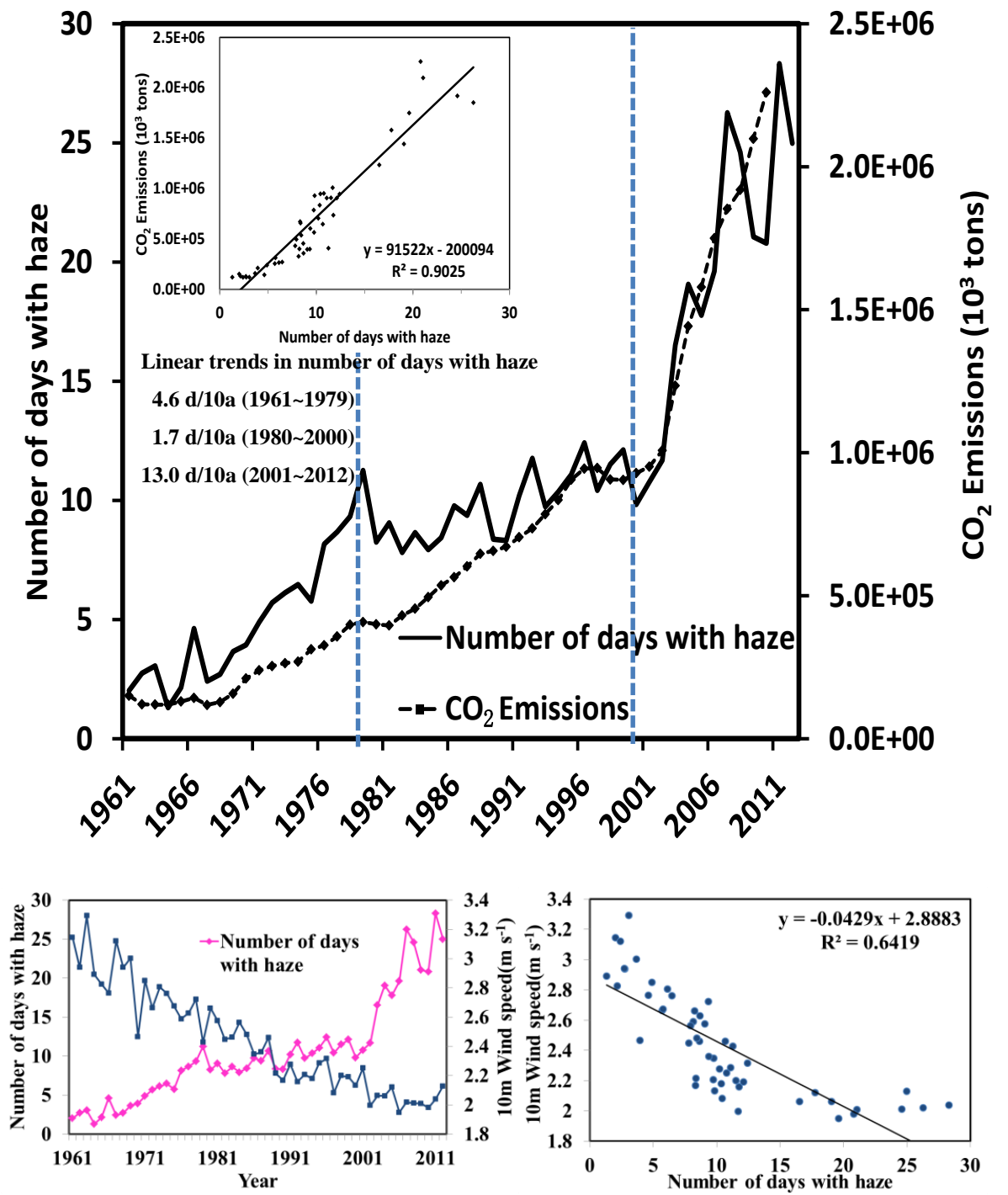

Figure 1. Interannual variations in the total $\mathrm{CO}_{2}$ emissions in mainland China and the haze event frequency averaged in the $\mathrm{CEC}$ region over 1961-2012 with their relationship in the inserted figure (upper panel). The Chinese $\mathrm{CO}_{2}$ emission data source: http://cdiac.ornl.gov/ CO2_Emission/timeseries/national. Two blue dotted lines separate the time series into three phases of the 1960s-1970s, the 1980s-1990s and the twenty-first century. Interannual variations in wind at $10 \mathrm{~m}$ (blue line) and the number of days with haze (red line) in the CEC over 1961-2012 (lower-left panel) and their scatter plot (lower-right panel).

logical variables ( $U, V$ and $W$ components of wind and air temperature) are calculated to build their horizontal and vertical distributions of correlations. Zonal, meridional and vertical components of the correlation vector are respectively derived through the correlation coefficients of the TP heat source column to $U-, V$ - and $W$-components of vector of wind and air temperature, indicating the changes in wind and air temperature induced by the TP thermal forcing.

In the modeling study, we used the global air quality model system GEM-AQ/EC, which is an integration of gas-phase chemistry and aerosol modules in the meteorological model GEM (Global Environmental Multiscale weather prediction model of Environment Canada). Full details of the develop- ment and evaluation of GEM-AQ/EC are given by Gong et al. (2012) . The validations of 10-year (1995-2004) GEM$\mathrm{AQ} / \mathrm{EC}$ modeling prove that the model provided satisfactory simulations of the distribution and variation of global and regional aerosols (Zhao et al., 2012; Gong et al., 2012). Regional variations of aerosols in east Asia are reasonably captured by the GEM-AQ/EC model, compared to the observed aerosol concentrations and aerosol optical depth.

Air quality change is generally driven by two factors: pollutant emissions and meteorology. In order to exclude the emission influence on interannual variations of aerosols, a sensitivity simulation with GEM-AQ/EC is designed without year-to-year changes in anthropogenic aerosol emissions 

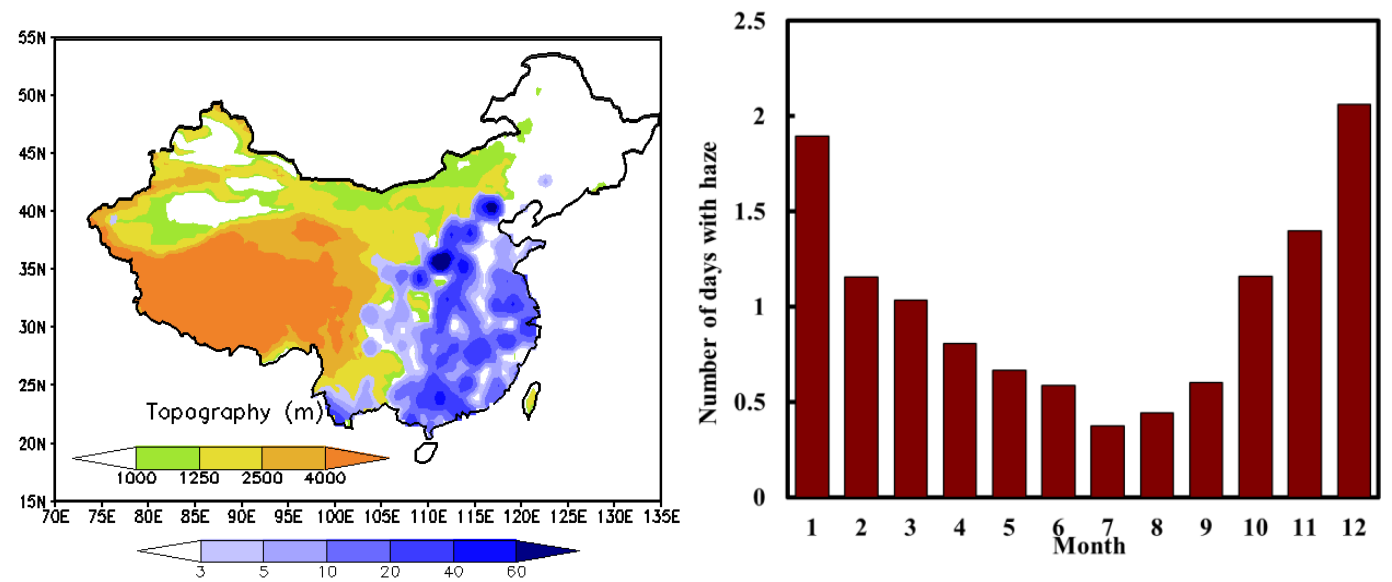

Figure 2. Distribution of annual haze event frequency (days per year) averaged over 1961-2012 in China, and Chinese topography of the TP and the Loess Plateau with altitudes is shown with yellow shades (left panel). Monthly variation of haze frequency averaged from 1961-2012 over the CEC region (right panel).

from 1995 to 2004 for an assessment of the impact of the TP warming on air quality change in China. The sensitivity simulation experiment of GEM-AQ/EC was configured with 28 hybrid vertical levels and the model top at $10 \mathrm{hPa}$, as well as the horizontal model grids in a global uniform resolution of $1^{\circ} \times 1^{\circ}$. The GEM-AQ/EC was run with the fully nudged variables of wind, temperature, pressure and water vapor of NCEP reanalysis meteorology every $24 \mathrm{~h}$ from 1995 to 2004.

\section{Results and discussion}

In this section, we identify the contributions of pollutant emissions and climate change to interannual haze variations (Sect. 3.1), reveal a climatological "susceptible region" for haze formation in China (Sect. 3.2), analyze the relationships between TP's thermal forcing and haze over CEC (Sect. 3.3) and investigate the TP warming that induces favorable meteorology for CEC's haze (Sect. 3.4) based on the meteorological observations. In order to more convincingly demonstrate the observed results, Sect. 3.5 presents the results of a sensitivity simulation experiment about impacts of the TP's thermal forcing on CEC's aerosol variations.

\subsection{Contributions of pollutant emissions and climate change to interannual haze variations in China}

China has experienced the huge increases in $\mathrm{CO}_{2}$ emissions from fossil fuel combustion with the certain attendant pollutant emissions and aerosol loading over recent decades (upper panel of Fig. 1), which has a direct physical link to more frequent haze occurrences in situ in China. The regional emissions of air pollutants contribute largely to the haze pollution in CEC with a high coefficient of determination, $R^{2}=0.9025$, between interannual variations of haze frequency and $\mathrm{CO}_{2}$ emission in China (upper panel of Fig. 1), reflecting that the frequent haze events are strongly associated with the large increases in anthropogenic pollutant emissions in recent decades.

Accompanied by an unceasing increase in the Chinese pollutant emissions during recent decades, the significant interannual variations of haze occurrences in CEC over recent decades could be separated into three interdecadal phases with the trends of slow ascending (4.6d/10a) from the $1960 \mathrm{~s}$ to 1970 s, less changing $(1.7 \mathrm{~d} / 10 \mathrm{a})$ during the $1980 \mathrm{~s}-1990 \mathrm{~s}$ and sharply rising with a trend reaching $13.0 \mathrm{~d} / 10$ a going into the twenty-first century (upper panel of Fig. 1). Although a continuous increasing trend in the pollutant emissions has been evident over recent decades, the haze variations in CEC have evolved with the different trends of slow, less and sharply ascending over three interdecadal periods, implying that climate change could also play an important role in the variations of haze events in CEC, independent of the anthropogenic dimension of pollutant emission sources related to the rapid industrialization of China. A steady decline of east Asian monsoon winds is negatively correlated to haze occurrences in the CEC with the coefficient of determination, $R^{2}=0.6419$, passing the confidence level of $99.9 \%$ (lower panel of Fig. 1), indicating a consequence of east Asian monsoon climate change to CEC haze pollution.

\subsection{A climatological susceptible region for haze formation in China}

Examination of ground-based observations of the frequency of haze events from 1961 to 2012 (CMA, 2010) reveals that the haze air pollution in China typically has the highest levels in the CEC region, covering a vast area from the eastern edges of the TP and the Loess Plateau to China's Pacific coast, and haze occurrences in CEC oscillate seasonally between the peak in winter and the low in summer (Fig. 2). 

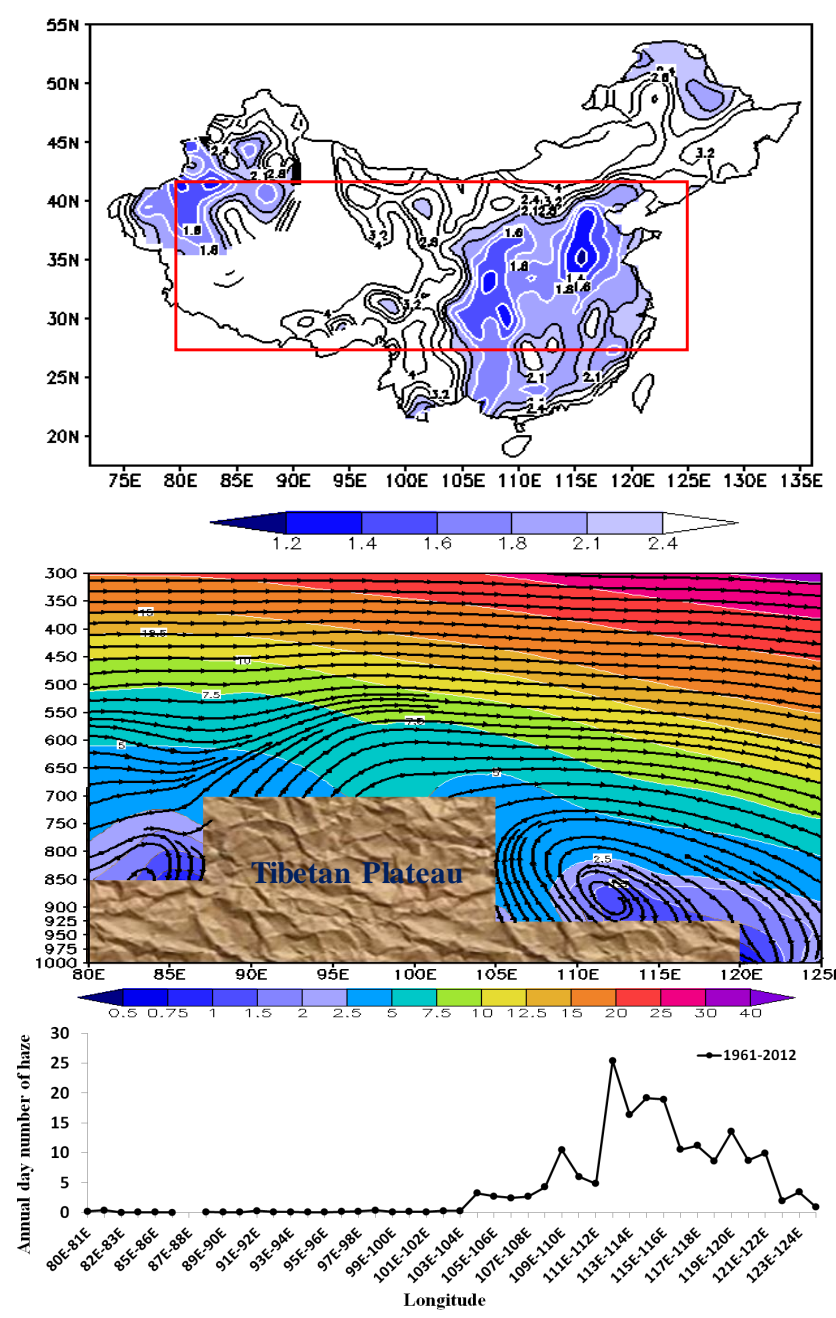

Figure 3. Near-surface wind speed distribution $\left(\mathrm{m} \mathrm{s}^{-1}\right)$ averaged over 1961-2012 in China with the red rectangle marking the region for cross sections in the middle and lower panels (upper panel). Cross sections of horizontal wind speed $\left(\mathrm{m} \mathrm{s}^{-1}\right.$; filled color contours) and vertical circulations illustrated by stream lines (middle panel) and zonal variations of annual haze event frequency (lower panel) at $27-41^{\circ} \mathrm{N}$ averaged over 1961-2012. Note that near-surface vertical and horizontal winds are not illustrated well here due to north-south variations in the terrain and approximation of the location of the TP in this figure. All fields are for the annual averages.

Based upon these climate data, we could climatologically regard the CEC, with the lowlands harbored by the upstream plateaus of western China, as a large-scale susceptible region of frequent haze events in China (left panel of Fig. 2). The upper panel of Fig. 3 shows that low average wind speeds tend to be coincident with the centers of pollutant haze events over the CEC (left panel of Fig. 2), reflecting the climatological susceptible region of haze occurrences in connection with a stagnation area in the lower troposphere in China.
Due to the influence of the TP terrain on the typical westerly winds in this region, the air flowing from the windward plateaus descends in a north-south-oriented zone between about 110 and $125^{\circ} \mathrm{E}$ (middle panel of Fig. 3). Accompanying this strong downward current are weak winds in the near-surface layers that lie in the lee side of the plateaus. These air flow and wind condition lead to development of a "harbor" that accumulates air pollutants in the CEC region. The weak wind and downward current areas coincide well with the centers of frequent haze events in China (middle and lower panels of Fig. 3). The susceptible region of haze events over the CEC region from the eastern edge of the plateaus to the lower flatlands is associated with the harbor effect of the unique TP topography under specific meteorological conditions that trap air pollutants.

Because haze is, climatologically, mostly a winter phenomenon in the CEC (right panel of Fig. 2), the following analysis on the TP's climate effect on haze pollution in CEC and the related mechanisms is focused on the winter season.

\subsection{Relationships between TP's thermal forcing and haze over CEC}

As a vast elevated landmass, the TP acts thermodynamically as a synoptic-scale wintertime cooling source protruding into the free atmosphere (Qiu, 2008; Ruddiman and Kutzbach, 1989; Yeh et al., 1957; Liu and Chen, 2000). The TP region, as a wintertime cooling source (negative values of apparent heat source $Q_{1}$ ), has been experiencing a warming trend over recent decades, especially since 2001 (upper left panel of Fig. 4). A striking climate warming over the TP during the last decades has been revealed by many studies (Liu and Chen, 2000; Duan et al., 2006; Yan and Liu, 2014).

Against the backdrop of global climate change, the question may be posed: does the warming of the TP region cause changes in the atmospheric environment in China, resulting in more frequent haze events in the CEC? The historical data analysis indicates that a significant correlation exists between the wintertime cooling source represented by the apparent heat source column $Q_{1}$ integrated over the TP and the number of haze days averaged regionally in the CEC over recent decades (upper panel of Fig. 4). It is also found in the upper panel of Fig. 4 that the changes of wintertime $Q_{1}$ over the TP were reversed from cooling to warming in the late 1990s, which could be connected with the trends in haze occurrences with a less changing trend over the 1980s-1990s and a sharp increasing trend during the twenty-first century in China under the increases in pollutant emission levels (upper panel of Fig. 1). Based on the composite analysis on the haze frequencies in winter with positive and negative anomalies in wintertime cooling source of the TP, the haze increasing and decreasing incidences over the CEC are found to be in good agreement with the positively and negatively anomalous TP cooling sources (lower panel of Fig. 4). The frequency of 

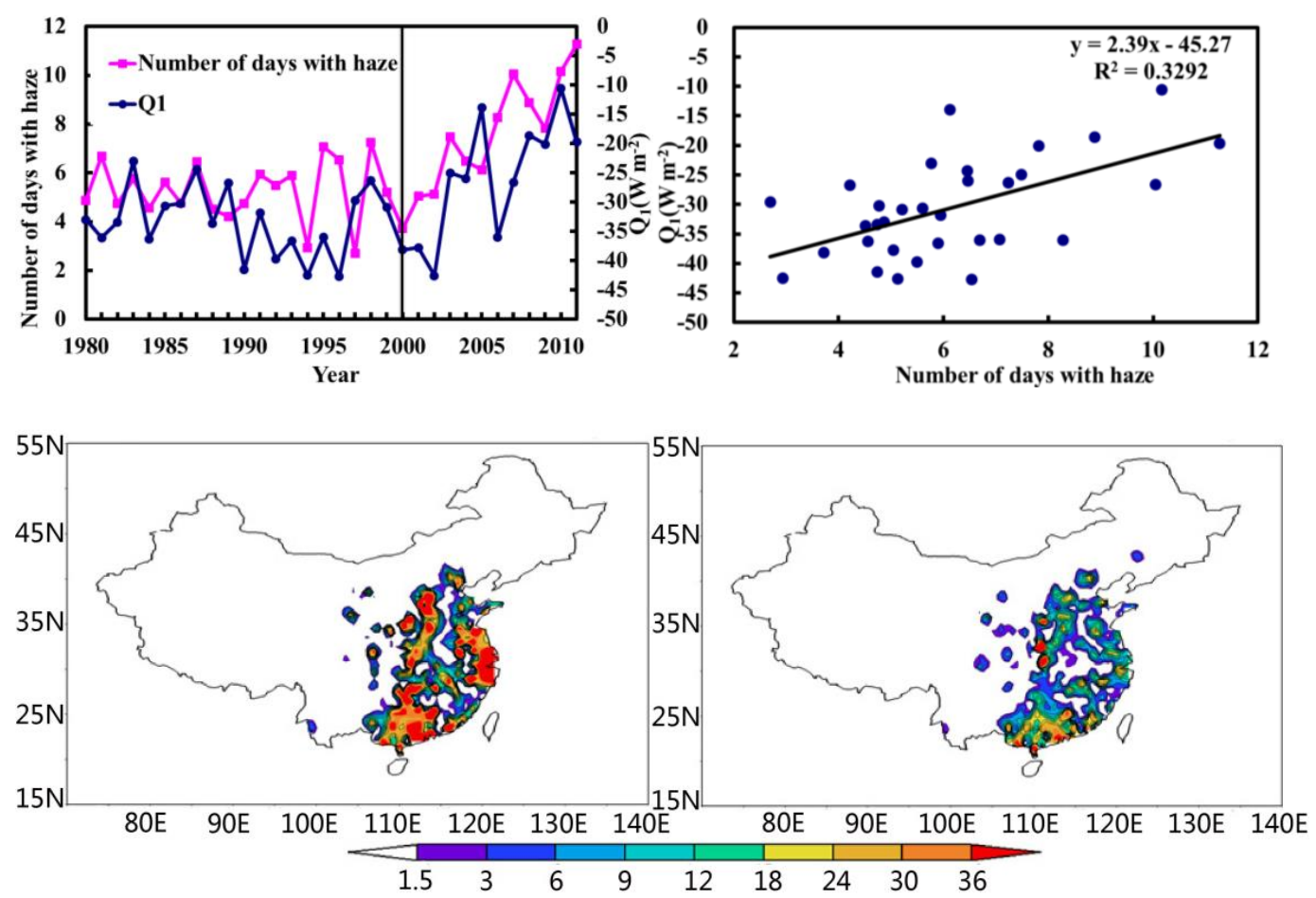

Figure 4. Interannual variability in the apparent heat source $Q_{1}$ (the negative values denote cooling) integrated vertically over the TP and haze event frequency averaged in the CEC in winter (December, January and February) over 1980-2012 and their correlation (upper panel). The haze frequencies (days) averaged in five winters with most positive (lower left panel) and most negative $Q_{1}$ anomalies (lower right panel) on the TP relative to the mean haze frequency from 1980 to 2012.

haze events over the CEC region is positively correlated with climatic warming over the TP.

\subsection{The TP warming that induces favorable meteorology for CEC's haze}

Further analyses provide information on the mechanisms relating climatic warming of the TP to enhancement in haze occurrence in the CEC. The favorable meteorology for haze occurrences is well known to be lower wind speeds, weaker vertical mixing, stronger subsidence, higher air humidity and more stable low-level stratification. We are still pondering the question whether climatic warming of the TP could strengthen the aforementioned meteorological conditions downstream for frequent haze events in the CEC to reveal the mechanism of how thermal anomalies of the TP in climate change influence the incidence of haze over the CEC.

The east Asian winter monsoon, which climatologically prevails over the CEC, typically maintains near-surface northeastern winds (Ding, 1994). In the upper panel of Fig. 5, two horizontal components of the correlation vector are derived through two correlation coefficients of $Q_{1}$ to $U$ and $V$ surface wind components, respectively, where the arrow length denotes the combined correlation, with a longer arrow implying a better correlation, and the arrow direction showing the direction of anomalous wind induced by the TP ther- mal effect. The correlation vector over the CEC in the upper panel of Fig. 5 indicates that the variations of thermal forcing over the TP could give rise to the weakening winter monsoon winds (southwest wind anomalies) induced by changes of $Q_{1}$ over the TP. Furthermore, the anomalous south wind components resulting from climate change in the TP (positive correlations of $Q_{1}$ to $V$-wind components in upper panel of Fig. 5) can enhance transport of water vapor from the oceans to the CEC (Niu et al., 2010). By increasing the moisture in the lower troposphere driven by the strong vapor transport (Hung and Kao, 2010) (lower panel of Fig. 5), in addition to decline in the east Asian winter monsoon with weak advection of cold air, haze formation can be enhanced. (Zhao et al., 2013; Xiao et al., 2011).

The upper panels of Fig. 6 present the results of composite analysis on vertical variations in air temperature in five winters, with the most positive and the most negative anomalies in the TP cooling source. The air temperature changes with upper warmer and lower cooler pattern are found in the middle and lower troposphere over the CEC region in winter with positive $Q_{1}$ anomalies on the TP, and an inverse structure of the CEC air temperature changes in winter with negative $Q_{1}$ anomalies on the TP (upper panel of Fig. 6). The TP's warming and cooling anomalies could lead to a "warm shield" and a "cool shield" in the atmosphere over the CEC. The correlation analyses of observation data over 1981-2012 confirm 

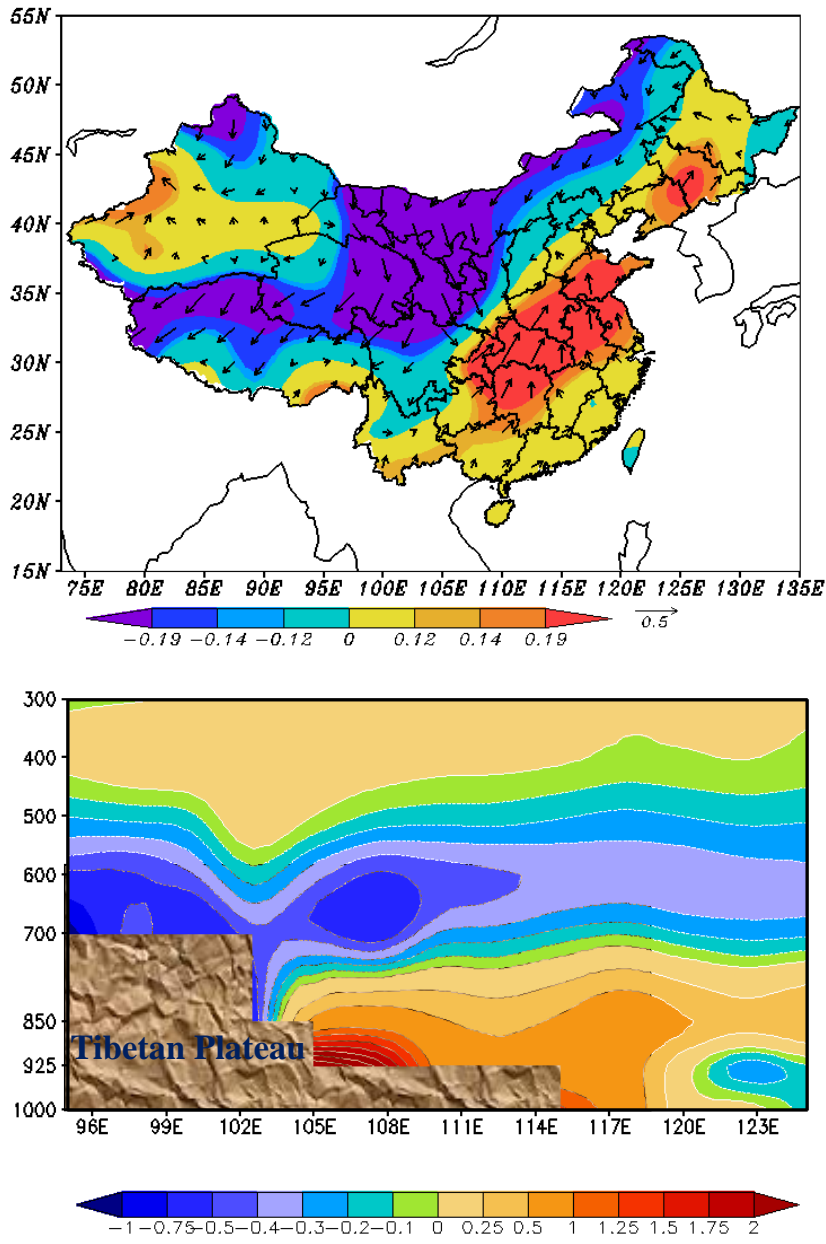

Figure 5. The distributions of the interannual correlations of the apparent heat source $Q_{1}$ over the TP to the local $V$-component of surface wind in winter over 1961-2012 (color shading). Arrows denote correlation vectors (showing both correlation coefficients of $Q_{1}$ to $U$ - and $V$-surface wind components) in China. The correlation coefficients of $0.12(-0.12), 0.14(-0.14)$ and $0.19(-0.19)$ respectively passing the significance levels of 90,95 and $99 \%$. A vertical section of the trends in vapor content ( $\mathrm{g} \mathrm{kg}^{-1}$ per 10 years) in winter over $1961-2012$ averaged along $27-41^{\circ} \mathrm{N}$ (lower panel).

that the vertical structure of anomalous air temperature, similar to that which induced the TP's positive thermal effect (upper-left panel of Fig. 6) with a "warm shield" intensifying the subsidence in the lower troposphere, is responsible for the frequent haze occurrences over the CEC (lower panel of Fig. 6). Associated with the warming TP, the vertical variations of air temperature with upper warmer and lower cooler could easily build an inversion layer in the atmosphere over the polluted CEC, which results in a more stably stratified atmosphere in this region (Fig. 6). Heavy haze pollution processes in winter are highly related with the existence of the atmospheric inversion layer (Xu et al., 2003).

The cumulative consequences of weakening winter monsoon winds and intensifying downward air flows are a more humid and more stable atmosphere, as the favorable meteorological conditions for haze formation would be expected to strengthen the air pollutant harbor effect of the TP and increase the number and severity of haze events in the CEC. Therefore, the haze formation over CEC is significantly modulated by the TP's climate change under the increase and even without changes in the current levels of anthropogenic pollutant emissions.

\subsection{A sensitivity simulation experiment on effect of the TP warming}

In order to more convincingly demonstrate the connection of the TP warming to the haze frequency over CEC, a sensitivity simulation, by employing the global air quality model GEM$\mathrm{AQ} / \mathrm{EC}$, is designed to isolate the emission influence on interannual variations of aerosols, where the monthly data of anthropogenic emissions by fossil fuel and biomass burning, as well as the sulfate emissions compiled using EDGAR2.0, are introduced without any interannual changes from 1995 to 2004 (Gong et al., 2012). The results of this sensitivity simulation are used to assess the impact of climate change on interannual change of air quality over CEC in this study.

Haze and aerosol changes are determined by both pollutant emission and meteorology, and the effects of meteorology are difficult to separate from aerosol observations. The 10year GEM-AQ/EC simulation without interannual changes in the anthropogenic emissions provides a possibility to identify the meteorological effect on the interannual variations of aerosols. To investigate the implications of TP's climate change for interannual aerosol variations in CEC's haze, a composite analysis of surface aerosol concentrations over CEC (Fig. 7) were performed for two winters with negative TP $Q_{1}$ anomalies $(1996,2002)$ and two winters with positive TP $Q_{1}$ anomalies $(1998,2003)$ during the simulation period of 1995-2004 according to the interannual $Q_{1}$ changes over the TP (Fig. 4). As designed in the sensitivity simulation, the pollutant emissions in lower TP $Q_{1}$ anomalies (1996, 2002) and higher TP $Q_{1}$ anomalies $(1998,2003)$ are the same as in the simulation with the emission inventory data set EDGAR2.0. (Gong et al., 2012) . Because the effect of emissions was singled out in the interannual aerosol variations modeled in the sensitivity simulation experiment, the simulated variations in aerosol concentrations over CEC could be purely attributed to the changes of meteorological drivers in the context of changing climate. The analysis results show that the TP heating anomalies could lead to enhancements of $30-45 \%$ in wintertime surface aerosol concentrations over the CEC region compared to the winters with the TP cooling anomalies (Fig. 7). Because changes of aerosol levels in the surface atmosphere determine haze formation, this sensitivity simulation confirmed that the frequent haze in China with the significantly interannual variations is closely related to thermal forcing by the TP, and climate change of the TP could 

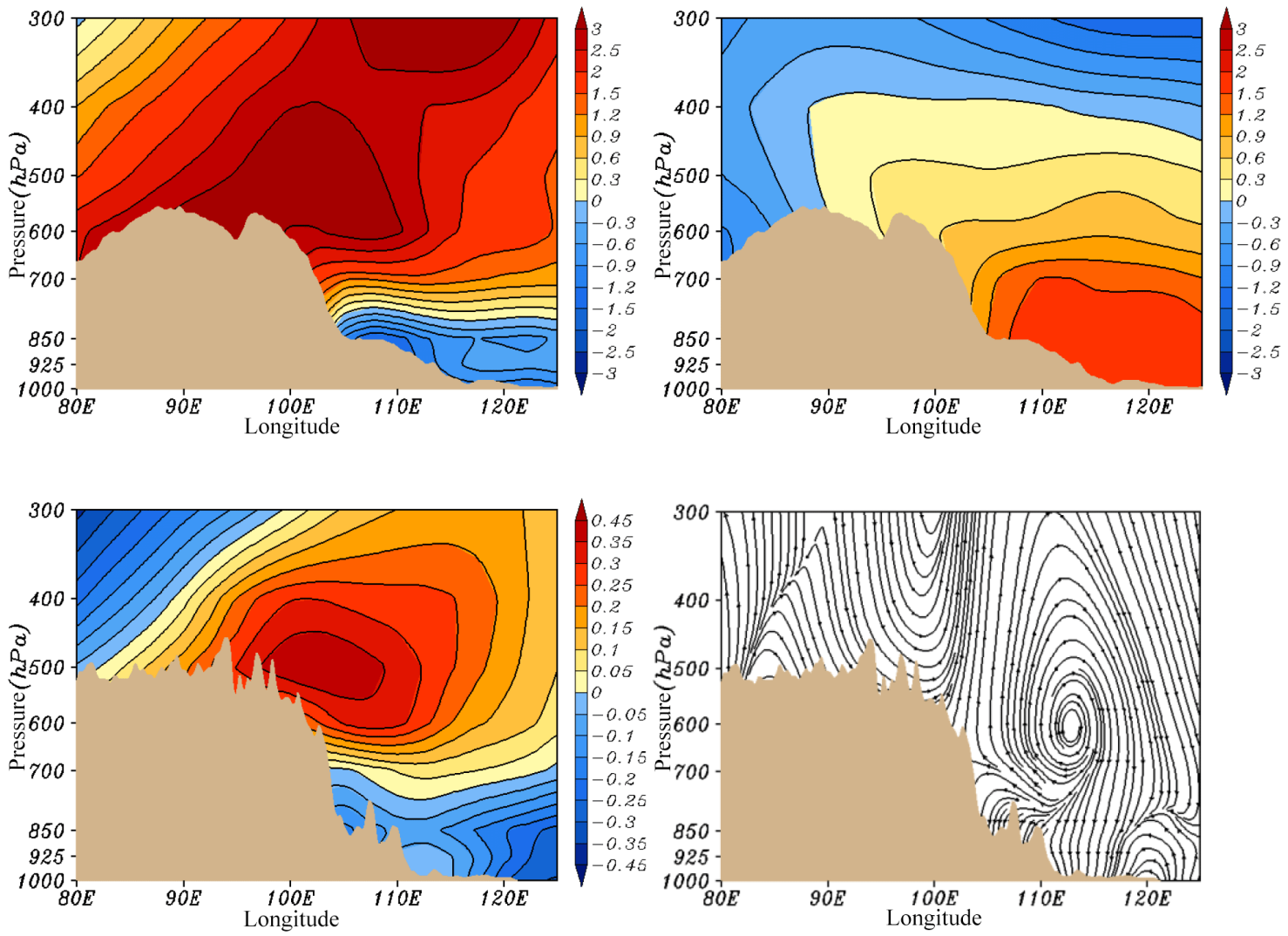

Figure 6. Vertical sections of the anomalous air temperature $\left({ }^{\circ} \mathrm{C}\right.$ ) averaged along $27-41^{\circ} \mathrm{N}$ in five winters with most positive (upper left panel) and most negative $Q_{1}$ anomalies (upper right panel) on the TP from 1980 to 2012, and vertical sections of the correlations of the number of haze days with air temperature (lower left panel) and vertical circulations (lower right panel) in winter from 1980 to 2012.

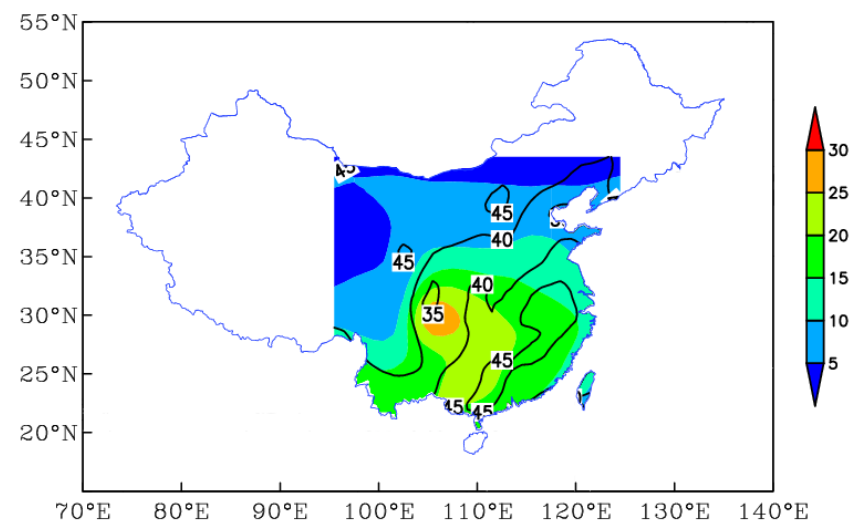

Figure 7. The percentages (\%; contour lines) of differences of surface aerosol concentrations between the winters of 1998 and 2003 with positive $Q_{1}$ anomalies and the winters of 1996 and 2002 with negative $Q_{1}$ anomalies on the TP relative to the surface aerosol levels averaged over the winters of 1996, 1998, 2002 and 2003 ( $\mu \mathrm{g} \mathrm{m}^{-3}$; color contours), modeled by the sensitivity simulation experiment with GEM-AQ/EC. intensify pollutant haze in China even without increases in the current anthropogenic pollutant emissions.

\section{Conclusions}

Based on observational data over recent decades, we identify the CEC region, the lower flatlands along the eastern plateau edges in China, as a climatological large-scale susceptible region of pollutant haze, connected with downward currents and weak near-surface winds as a consequence of the harbor impact of large TP topography on midlatitude westerlies. The climate analysis reveals that the increasingly frequent haze in the CEC region is related with decreasing winter monsoon winds, intensifying descending air and increasing atmospheric stability in the lower troposphere over the CEC in association with the plateau's thermal anomalies. Climate impact of the TP's mechanical and thermal forcing, driving changes in atmospheric circulation and meteorological conditions downstream, potentially contributes to the increasing trend in haze events in China. A sensitivity simulation also confirmed that the frequent haze in CEC with the significantly interannual variations is closely connected with thermal forcing by the TP. 
The Chinese government has been making great strides in reducing emissions and mitigating air pollution. However, the interplay of China's unique landform distribution with climate change and its associated more extreme weather events could impair the effectiveness of air pollution control measures in China. With the influence of the TP climate change, the $\mathrm{CEC}$ region is facing a bigger challenge to realize air quality maintenance plans. The TP harbor effect and climate change should be considered in making decisions on the locations of new industrial facilities for development planning in China in order to preferentially reduce anthropogenic emissions in the susceptible region of haze and in turn reduce the number and severity of haze events in the central-eastern region of China.

In this preliminary study based on long-term observational data and a sensitivity simulation experiment, we investigate a relationship between the haze pollution in China and the TP's environment and climate changes. It should be emphasized that considering the quality of reanalysis data over and around the TP, a comparison between NCEP/NCAR and other reanalysis data sets such as JRA-25, ERA-Interim or MERRA is necessary in further work. Understanding the TP's thermal forcing changes and east Asian monsoon declines is a challenging topic. The impacts of the TP's climate change on air quality in China could be further studied in relation to the shifts in weather patterns, pollutant emissions, depositions and chemical reactions in the atmosphere to comprehensively understand the meteorological drivers of air quality in a changing climate and also to consider the ocean-related impacts of climate change.

Acknowledgements. This research is jointly supported by the Projects of Nature Science Fund of China (no. 41130960; no. 91544109), Chinese National Science and Technology Project (2014BAC22B04), the projects of China Special Fund for Meteorological Research (GYHY201406001) and Environmental Protection (HY14093355; 201509001) in the Public Interest and the Priority Academic Program Development of Jiangsu Higher Education Institutions (PAPD). This paper is the ESMC publication number 087. We acknowledge the reviews of Xuhui Lee (Yale Uni.), Beth Hall (ISWS) and the anonymous reviewers.

Edited by: J. Huang

\section{References}

Chen, S., Huang, J., Zhao, C., Qian, Y., Leung, L. R., and Yang, B.: Modeling the transport and radiative forcing of Taklimakan dust over the tibetan plateau: a case study in the summer of 2006, J. Geophys. Res., 118, 797-812, doi:10.1002/jgrd.50122, 2013a.

Chen, Y., Ebenstein, A., Greenstone, M., and Li, H.: Evidence on the impact of sustained exposure to air pollution on life expectancy from China's Huai River policy, P. Natl. Acad. Sci. USA, 110, 12936-12941, doi:10.1073/pnas.1300018110, 2013b.
CMA: China Meteorological Administration, National meteorological standard of the People's Republic China: Observation and forecasting levels of haze, QX-T 113-2010, 2010 (in Chinese).

Ding, Y. H.: Monsoons over China, Kluwer Academic Publishers, Dordrecht/Boston/London, 1-290, 1994.

Ding, Y. H. and Liu, Y. J.: Analysis of long-term variations of fog and haze in China in recent 50 years and their relations with atmospheric humidity, Science China: Earth Sciences, 57, 36-46, doi:10.1007/s11430-013-4792-1, 2014.

Doyle, M. and Dorling, S.: Visibility trends in the UK 1950-1997, Atmos. Environ., 36, 3161-3172, 2002.

Duan, A., Wu, G. X., Zhang, Q., and Liu, Y.: New proofs of the recent climate warming over the Tibetan Plateau as a result of the increasing greenhouse gases emissions, Chinese Sci. Bull., 51, 1396-1400, 2006.

Gong, S. L., Lavoué, D., Zhao, T. L., Huang, P., and Kaminski, J. W.: GEM-AQ/EC, an on-line global multi-scale chemical weather modelling system: model development and evaluation of global aerosol climatology, Atmos. Chem. Phys., 12, 8237-8256, doi:10.5194/acp-12-8237-2012, 2012.

$\mathrm{Gu}$, L.: Half of Chinese live in haze: report, China News, available at: http://www.ecns.cn/cns-wire/2013/07-12/72889.shtml, last access: 12 July 2013.

Hansen, J. and Nazarenko, L.: Soot climate forcing via snow and ice albedos, P. Natl Acad. Sci. USA, 101, 423-428, 2004.

Huang, J., Minnis, P., Chen, B., Huang, Z., Liu, Z., Zhao, Q., Yi, Y., and Ayers, J. K.: Long-range transport and vertical structure of Asian dust from CALIPSO and surface measurements during PACDEX, J. Geophys. Res., 113, D23212, doi:10.1029/2008JD010620, 2008.

Huang, R.-J., Zhang, Y., Bozzetti, C., Ho, K.-F., Cao, J.-J., Han, Y., Daellenbach, K. R., Slowik, J. G., Platt, S. M., Canonaco, F., Zotter, P., Wolf, R., Pieber, S. M., Bruns, E. A., Crippa, M., Ciarelli, G., Piazzalunga, A., Schwikowski, M., Abbaszade, G., SchnelleKreis, J., Zimmermann, R., An, Z., Szidat, S., Baltensperger, U., Haddad, I. E., and Prevot, A. S. H.: High secondary aerosol contribution to particulate pollution during haze events in China, Nature, 514, 218-222, doi:10.1038/nature13774, 2014.

Hung, C.-W. and Kao, P.-K.: Weakening of the winter monsoon and abrupt increase of winter rainfalls over northern taiwan and southern china in the early 1980s, J. Climate, 23, 2357-2367, doi:10.1175/2009JCLI3182.1, 2010.

Kan, H., Chen, R., and Tong, S.: Ambient air pollution, climate change, and population health in China, Environ. Int., 42, 10-19, doi:10.1016/j.envint.2011.03.003, 2012.

Lau, K. M., Kim, M. K., and Kim, K. M.: Asian summer monsoon anomalies induced by aerosol direct forcing: the role of the Tibetan Plateau, Clim. Dynam., 26, 855-864, doi:10.1007/s00382006-0114-z, 2006

Lau, W. K. M., Kim, M. K., Kim, K. M., and Lee, W. S.: Enhanced surface warming and accelerated snow melt in the Himalayas and Tibetan Plateau induced by absorbing aerosols, Environ. Res. Lett., 5, 025204, doi:10.1088/1748-9326/5/2/025204, 2010.

Liu, X. and Chen, B.: Climatic warming in the Tibetan Plateau during recent decades, Int. J. Climatol., 20, 1729-1742, 2000.

Liu, Z., Liu, D., Huang, J., Vaughan, M., Uno, I., Sugimoto, N., Kittaka, C., Trepte, C., Wang, Z., Hostetler, C., and Winker, D.: Airborne dust distributions over the Tibetan Plateau and surrounding areas derived from the first year of CALIPSO lidar obser- 
vations, Atmos. Chem. Phys., 8, 5045-5060, doi:10.5194/acp-85045-2008, 2008.

NDRC: Chinese National Development and Reform Commission Report, Grim situation in energy-saving and emissionreduction and huge potential for development, available at: http://www.ndrc.gov.cn/fzgggz/hjbh/hjjsjyxsh/201307/ t20130710_549556.html, last access: 31 July 2013 (in Chinese).

Niu, F., Li, Z., Li, C., Lee, K.-H., and Wang, M.: Increase of wintertime fog in China: Potential impacts of weakening of the Eastern Asian monsoon circulation and increasing aerosol loading, J. Geophys. Res.-Atmos., 115, D00K20, doi:10.1029/2009jd013484, 2010.

Oey, L.-Y., Chang, M.-C., Chang, Y.-L., Lin, Y.-C., and Xu, F.-H.: Decadal warming of coastal Chlf of the Chinese populatith winter monsoon and currents, Geophys. Res. Lett., 40, 6288-6292, doi:10.1002/2013GL058202, 2013.

Park, S.-U., Cho, J.-H., and Park, M.-S.: Analyses of high aerosol concentration events (dense haze/mist) occurred in East Asia during 10-16 January 2013 using the data simulated by the Aerosol Modeling System, International Journal of Chemistry, 03, 10-26, 2013.

Pope, C. A. and Dockery, D. W.: Air pollution and life expectancy in China and beyond, P. Natl. Acad. Sci. USA, 110, 12861-12862, doi:10.1073/pnas.1310925110, 2013.

Qian, Y., Flanner, M. G., Leung, L. R., and Wang, W.: Sensitivity studies on the impacts of Tibetan Plateau snowpack pollution on the Asian hydrological cycle and monsoon climate, Atmos. Chem. Phys., 11, 1929-1948, doi:10.5194/acp-11-19292011, 2011.

Qiu, J.: China: The third pole, Nature, 454, 393-396, 2008.

Ramanathan, V. and Carmichael, G.: Global and regional climate changes due to black carbon, Nat. Geosci., 1, 221-227, 2008.

Ruddiman, W. F. and Kutzbach, J. E.: Forcing of late Cenozoic northern hemisphere climate by plateau uplift in southern Asia and the American west, J. Geophys. Res., 18409-18427, doi:10.1029/JD094iD15p18409, 1989.

Schichtel, B. A., Husar, R. B., Falke, S. R., and Wilson, W. E.: Haze trends over the United States 1980-1995, Atmos. Environ., 35, 5205-5210, 2001.

Tagaris, E., Liao, K. J., Delucia, A. J., Deck, L., Amar, P., and Russell, A. G.: Potential impact of climate change on air pollutionrelated human health effects, Environ. Sci. Technol., 43, 49794988, 2009.

Wang, Y., Zhang, R. Y., and Saravanan, R.: Asian pollution climatically modulates midlatitude cyclones following hierarchical modeling and observational analysis, Nature Communications, 5, 1-7, doi:10.1038/ncomms4098, 2014.

Wang, H.-J., Chen, H.-P., and Liu, J.-P.: Arctic sea ice decline intensified haze pollution in Eastern China, Atmos. Oceanic Sci. Lett., 8, 1-9, doi:10.3878/AOSL20140081, 2015.

Wu, G. X., Liu, Y., He, B., Q. Bao, Duan, A., and Jin, F.-F.: Thermal Controls on the Asian Summer Monsoon, Scientific Reports, 2, 404, doi:10.1038/srep00404, 2012.

Xiao, Z.-M., Zhang, Y.-F., Hong, S.-M., Bi, X.-H., Jiao, L., Feng, Y.-C., and Wang, Y.-Q.: Estimation of the main factors influencing haze, based on a long-term monitoring campaign in Hangzhou, China, Aerosol Air Qual. Res., 11, 873-882, doi:10.4209/aaqr.2011.04.0052, 2011.
Xu, B., Cao, J. J., Hansen, J., Yao, T., Joswiaa, D. R., Wang, N., Wu, G., Wang, M., Zhao, H., Yang, W., Liu, X., and He, J.: Black soot and the survival of Tibetan glaciers, P. Natl. Acad. Sci. USA, 106, 22114-22118, 2009.

Xu, M., Chang, C.-P., Fu, C., Qi, Y., Robock, A., Robinson, D., and Zhang, H.: Steady decline of east Asian monsoon winds, 19692000: Evidence from direct ground measurements of wind speed, J. Geophys. Res., 111, D24111, doi:10.1029/2006JD007337, 2006.

Xu, X., Ding, G., Zhou, L., Zheng, X., Bian, L., Qiu, J., Yang, L., and Mao, J.: Localized 3D-structural features of dynamicchemical processes of urban air pollution in Beijing winter, Chinese Sci. Bull., 48, 819-825, 2003.

Xu, X., Lu, C., Shi, X., and Ding, Y.: Large-scale topography of China: A factor for the seasonal progression of the Meiyu rainband?, J. Geophys. Res., 115, D02110, doi:10.1029/2009JD012444, 2010.

Yan, L. and Liu, X.: Has climatic warming over the Tibetan Plateau paused or continued in recent years?, Journal of Earth Ocean and Atmospheric Sciences, 1, 13-28, 2014.

Yanai, M.: A detailed analysis of typhoon formation, J. Meteorol. Soc. Jpn., 39, 187-214, 1961.

Yanai, M. and Johnson, R. H.: Impacts of cumulus convection on thermodynamic fields, In The Representation of Cumulus Convection in Numerical Models of the Atmosphere, edited by: Emanuel, K. A. and Raymond, D. J., Vol. 24, AMS Monograph, 39-62, 1993.

Yanai, M. and Tomita, T.: Seasonal and Interannual Variability of Atmospheric Heat Sources and Moisture Sinks as Determined from NCEP-NCAR Reanalysis, J. Climate, 11, 463-482, 1998.

Yanai, M., Li, C. F., and Song, Z. S.: Seasonal heating of the Tibetan Plateau and its effects on the evolution of the Asian summer monsoon, J. Meteorol. Soc. Japan, 70, 319-351, 1992.

Ye, D. Z. and Wu, G. X.: The role of the heat source of the Tibetan Plateau in the general circulation, Meteorol. Atmos. Phys., 67, 181-198, 1998.

Yeh, T. C., Luo, S. W., and Chu, P. C.: The wind structure and heat balance in the lower troposphere over Tibetan Plateau and its surrounding, Acta Meteorol. Sin., 28, 108-121, 1957.

Zhang, R. H., Li, Q., and Zhang, R. N.: Meteorological conditions for the persistent severe fog and haze event over eastern China in January 2013, Science China: Earth Sciences, 57, 2635, doi:10.1007/s11430-013-4774-3, 2014.

Zhang, X. Y., Sun, J., Wang, Y., Li, W., Zhang, Q., Wang, W., Quan, J., Cao, G., Wang, J., Yang, Y., and Zhang, Y.: Factors contributing to haze and fog in China, Chinese Sci. Bull., 58, 1178-1187, 2013 (in Chinese).

Zhang, X. Y., Wang, J. Z., Wang, Y. Q., Liu, H. L., Sun, J. Y., and Zhang, Y. M.: Changes in chemical components of aerosol particles in different haze regions in China from 2006 to 2013 and contribution of meteorological factors, Atmos. Chem. Phys., 15, 12935-12952, doi:10.5194/acp-15-12935-2015, 2015.

Zhao, T. L., Gong, S. L., Huang, P., and Lavoué, D.: Hemispheric transport and influence of meteorology on global aerosol climatology, Atmos. Chem. Phys., 12, 7609-7624, doi:10.5194/acp12-7609-2012, 2012.

Zhao, X. J., Zhao, P. S., Xu, J., Meng, W., Pu, W. W., Dong, F., He, D., and Shi, Q. F.: Analysis of a winter regional haze event and 
its formation mechanism in the North China Plain, Atmos. Chem. Phys., 13, 5685-5696, doi:10.5194/acp-13-5685-2013, 2013.

Zhong, L., Su, Z., Ma, Y., Salama, M. S., and Sobrino, J. A.: Accelerated Changes of Environmental Conditions on the Tibetan Plateau Caused by Climate Change, J. Climate, 24, 6540-6550, 2011.
Zhu, J., Liao, H., and Li, J.: Increases in aerosol concentrations over eastern China due to the decadal-scale weakening of the East Asian summer monsoon, Geophys. Res. Lett., 39, L09809, doi:10.1029/2012GL051428, 2012. 